\title{
CLASIFICACIÓN DEL SUJETO DE DERECHO FRENTE AL AVANCE DE LA GENÓMICA Y LA PROCREÁTICA
}

\author{
Enrique Varsi Rospigliosi ${ }^{1}$
}

Resumen: El Derecho cataloga la vida humana de acuerdo al estado con el cual se presenta en sociedad con la finalidad de darle una adecuada seguridad. La teoría del sujeto de derecho se sustenta en la conceptualización jurídica de la vida humana. Como teoría, fue creada para reconocer una real y efectiva regulación jurídica a las relaciones que lleve a cabo el hombre en la sociedad, tomando en cuenta que la vida humana tiene numerosas formas de presentarse en sociedad. La vida es una, pero — sea biológica o social — adopta diversos estadios que merecen una regulación acorde con su estatus. Es esta esencia y forma como la vida se presenta en sociedad lo que permite categorizarla jurídicamente y de esto se encarga la teoría del sujeto de derecho. De esta forma se regula la vida humana en su verdadera esencia y dimensión; sin embargo, la biotecnología procreática y genómica vienen alterando su clásica taxonomía, variándolo, al presentar nuevos actores en un mundo de relación.

Palabras clave: sujeto de derecho, concebido, concepturus, moriturus, oriturus

\section{Subjects of rights classification facing genomic and proteomic development}

\begin{abstract}
Law categorizes human life according to its situation in society with the goal to provide adequate safety. The theory of the subject of rights is based on the juridical conceptualization of human life. As theory, it was created to recognize a real and effective legal regulation to human relations in society, taking into account that human life has many ways to appear in society. Life is one, but -be biological or social- it adopts diverse stages which deserves regulation according to their status. This essence and way in which life is presented allows its juridical categorization by the subject of rights theory. In this way, human life is regulated in its true essence and dimension; nevertheless, genomic and proteomic biotechnology have being altering their classic taxonomy, changing it when presenting new actors in a world of relations.
\end{abstract}

Key words: subject of rights, conceived, concepturus, moriturus, oriturus

\section{Classificação do sujeito de direito contra o avanço da genômica e da procriativa}

Resumo: O Direto cataloga a vida humana de acordo com o estado com a qual se apresenta na sociedade com a finalidade de dá-la um nível adequado de segurança. A teoria do sujeito de direito é baseada no conceito jurídico de vida humana. Como teoria, foi criada para reconhecer uma real e efetiva regulação jurídica das relaçóes realizadas pelo homem na sociedade, tendo em conta que a vida humana tem inúmeras maneiras de se apresentar na sociedade. A vida é uma, embora - seja biológica ou social - adota diferentes fases que merecem uma regulaçáo em conformidade com o seu estatuto. É essa essência e forma como a vida surge na sociedade é o que permite categorizá-la juridicamente e disso se encarga a teoria do sujeito do direito. Assim, regula a vida humana na sua verdadeira essência e dimensáo; no entanto, a biotecnología procriativa e genômica vem alterando sua taxonomia clássica, variando-a, introduzindo novos atores em um mundo de relaçôes.

Palavras-chave: sujeito de direito, concebido, concepturus, moriturus, oriturus

\footnotetext{
${ }^{1}$ Universidad de Lima, Comité Intergubernamental de Bioética de la UNESCO, Perú

Correspondencia: enriquevarsi@gmail.com
} 


\section{Generalidades}

Fernández Sessarego manifiesta, respecto del sujeto de derecho, que: "En la experiencia jurídica en la dimensión existencial- este ente o centro de referencia normativo no es otro que el ser humano antes de nacer o después de haberse producido este evento, ya sea que se le considere individualmente o como organización de personas"(1).

La atribución y determinación del status del subjectum iuris es problemática y controvertida al envolver tecnicismo e ideología. Ser sujeto para el Derecho implica estar en él, ser su parte, beneficiarse de una protección legal, hallarse en el centro de las funciones del Derecho. Situaciones éstas de los cuales goza y es merecedor el hombre. Soy, por ende, sujeto de derecho, por mi situación de ser humano, elemento indispensable, siendo reconocido como tal por la ley.

Se aprecia, con un criterio objetivo, que la clasificación del sujeto de derecho está dada de acuerdo con la esencia de la vida, a su estado, a cómo esta se presenta en la sociedad, a la variabilidad de sus manifestaciones - sea individual o colectivamente- - lo que ha obligado a que el Derecho le ofrezca, de acuerdo a su esencia, las medidas de seguridad y las reglas de desenvolvimiento adecuadas.

\section{Taxonomía genérica}

Los sujetos de derechos se estructuran de acuerdo con dos situaciones, dependiendo de su individualidad (unidad de vida) o la colectividad (agrupación de vida).

\section{De acuerdo a su conjunto}

\subsection{Sujetos de derecho individuales.}

La individualidad implica que el sujeto de derecho es el hombre en unidad; solo, sin compañía $y$, como tal, el Derecho le presta una seguridad en su calidad de ser social individual. En este rubro tenemos al concebido y la persona natural.

\subsection{Sujetos de derecho colectivos.}

A diferencia de la individualidad, el sujeto de derecho colectivo está determinado por un grupo de personas que buscan un objetivo en común para satisfacer sus intereses. Frente a esta situación se ha creado una estructura jurídica tendente a regular la pluralidad, la diversidad de personas, asumiendo un criterio legal y otorgar personería jurídica al grupo. En este rubro tenemos a la persona jurídica $y$ al ente no personificado.

\section{De acuerdo a su contenido}

\subsection{Sujetos de derecho común.}

Son los sujetos normales, corrientes, frecuentes, generales, así la persona natural, la jurídica y el ente no personificado.

\subsection{Sujetos de derecho especiales.}

Son los sujetos sui géneris, singulares, particulares, como el concebido. Y los llamados débiles jurídicos, personas vulnerables, como: el niño, el paciente, la mujer embarazada ${ }^{2}$, la persona con discapacidad mental, física o sensorial, los ancianos ${ }^{3}$, los desplazados ${ }^{4}$.

Para la Ley General de la Salud (art. V), en concordancia con el artículo 4 de la Constitución, son sujetos de derecho especiales en el cuidado de la salud: el nińo, la madre, el adolescente, el discapacitado, el anciano en situación de abandono social.

Es responsabilidad del Estado velar por el bienestar general (entiéndase salud) de estos seres humanos que, dada sus características físicas o psíquicas, se presentan como grupos vulnerables. Como los denomina la doctrina, son débiles juridicos o sujetos vulnerables que necesitan de protección especial, una tutela — venia debilium — respecto de acciones que pueden perjudicarlos.

En este sentido ha sido consagrado en la legislación, estableciéndose la atención preferente a las mujeres embarazadas, las niñas, niños, los adultos

\footnotetext{
${ }^{2}$ Las embarazadas, en la historia, han tenido una doble protección, en su calidad de mujeres y de gestantes. La pena de muerte se posterga hasta que se produzca el nacimiento y lex caesarea romana prescribía que la cesárea debía llevarse a cabo en una mujer moribunda con el fin de salvar al bebé.

${ }^{3}$ TC establece a través de su doctrina jurisprudencial vinculante de obligación judicial de actuar con celeridad en casos de personas adultas mayores Exp. 02214-2014-PA/TC.

${ }^{4}$ Ley $\mathrm{N}^{\circ} 28223$, sobre los desplazamientos internos y su Reglamento DS. No 004-2005-MIMDES.
} 
mayores en lugares de atención al público ${ }^{5}$, asimismo existe un tratamiento especial en materia de transporte para discapacitados, embarazadas y adultos mayores ${ }^{6}$.

Un interesante tratamiento, sobre el particular, presta la Constitución Política del Ecuador (2008) a los Derechos de las personas y grupos de atención prioritaria:

"Artículo 35. Las personas adultas mayores, niñas, niños y adolescentes, mujeres embarazadas, personas con discapacidad, personas privadas de libertad y quienes adolezcan de enfermedades catastróficas o de alta complejidad, recibirán atención prioritaria y especializada en los ámbitos público y privado. La misma atención prioritaria recibirán las personas en situación de riesgo, las víctimas de violencia doméstica y sexual, maltrato infantil, desastres naturales o antropogénicos. El Estado prestará especial protección a las personas en condición de doble vulnerabilidad".

Los débiles jurídicos, al no poder valerse por sí mismos, requieren de un tratamiento orgánico y uniforme dada su incapacidad, de forma tal que se establezcan en ejecución práctica del principio pro homine y debilis los medios de resguardo, dejando de lado su anterior categoría de non sujets de droit.

\section{De acuerdo a su esencia}

\subsection{Sujetos de existencia visible(2).}

Son las personas naturales, físicas o personas propiamente dichas(3). Podemos llamarlas "sujetos de derechos humanos".

\subsection{Sujetos de existencia ideal(2).}

Son las personas jurídicas, morales, civiles, ficticias, fingidas o no visibles. Podemos llamarlas "su-

${ }^{5}$ Ley No 27408 (DOEP, 24/01/2001), modificada por la Ley No 28683 (DOEP, 11/03/2006). En términos generales indica que en los lugares de atención al público las mujeres embarazadas, las niñas, nińos, las personas adultas mayores y con discapacidad, deberán ser atendidas y atendidos preferentemente. Asimismo, los servicios y establecimientos de uso público de carácter estatal o privado deben implementar medidas para facilitar el uso y/o acceso adecuado para las mismas.

${ }^{6}$ Ley No 28735 (DOEP, 18/05/2006), regula la atención de las personas con discapacidad, mujeres embarazadas y adultos mayores en los aeropuertos, aeródromos, terminales terrestres, ferroviarios, marítimos y fluviales y medios de transporte. jetos de derechos no humanos".

\section{De acuerdo a sus compromisos}

\subsection{Sujeto activo.}

El que hace, lleva a cabo. El obligado. "Sujeto de", connotación activa (sujeto actuante)(4). Es el titular de la acción: accionante, debitor.

\subsection{Sujeto pasivo.}

El que recibe, se favorece. El beneficiado. "Sujeto a”, connotación pasiva (sujetado)(4). Es el titular de la recepción: derechohabiente, creditor.

Sujeto activo y pasivo conforman la relación jurídica-subjetiva. Aunque, valgan verdades, es mejor hablar solo de "sujetos" sin la adjetivación de activo o pasivo, dado que ambos asumen compromisos. Los dos son pretensores.

\section{Taxonomía común}

El sujeto de derecho es un arquetipo, un modelo, genus (hiperónimo). Un molde del cual emergen otras categorías de sujetos, como el concebido, persona natural o jurídica, y la no inscrita, que son la especie, spes (hipónimo).

Se puede dividir en dos tipos de sujetos de derecho: individuales y colectivos.

Dentro de los individuales encontramos al concebido y a la persona natural; dentro de los colectivos, a la persona jurídica y al ente no personificado.

La categoría jurídica genérica de sujeto de derecho admite dos categorías jurídicas específicas, la que a su vez se divide en cuatro tipos de sujetos de derecho (tabla 1).

\begin{tabular}{|c|c|c|}
\hline \multicolumn{3}{|c|}{ Tabla 1: Categoría jurídica } \\
\hline Genérica & Específica & Tipos \\
\hline \multirow{4}{*}{ Sujeto de derecho } & \multirow{2}{*}{$\begin{array}{l}\text { Sujeto de derecho } \\
\text { individual }\end{array}$} & Concebido \\
\hline & & Persona natural \\
\hline & \multirow[b]{2}{*}{$\begin{array}{l}\text { Sujeto de derecho } \\
\text { colectivo }\end{array}$} & Persona jurídica \\
\hline & & $\begin{array}{l}\text { Ente no } \\
\text { personificado }\end{array}$ \\
\hline
\end{tabular}


La tipología de los sujetos de derecho en el Código Civil peruano del 84 es la del diagrama 1:

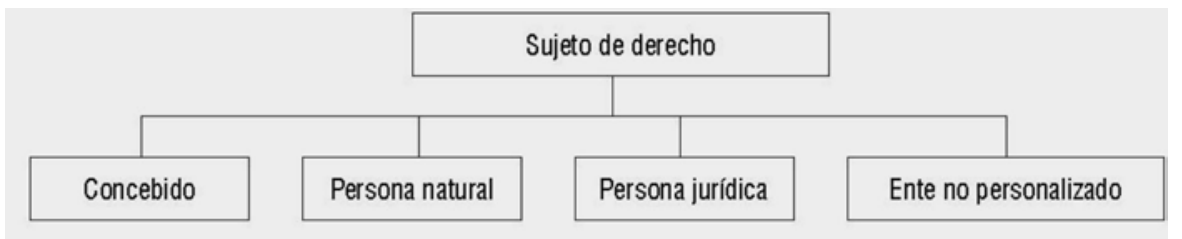

Efectivamente, es con la dación del Código de 1984 que se entiende como sujeto de derecho a todo ser humano, tomando en cuenta la diversidad de estados biosociales que puede asumir, tales como concebido, persona natural, persona jurídica y el ente no personificado. Esta es una clasificación que nos aproxima a la regulación del sujeto de derecho en nuestro Código y que, a modo de propuesta, proponemos la siguiente apreciación de taxonomía básica del sujeto de derecho en nuestro panorama civil nacional (diagrama 2):

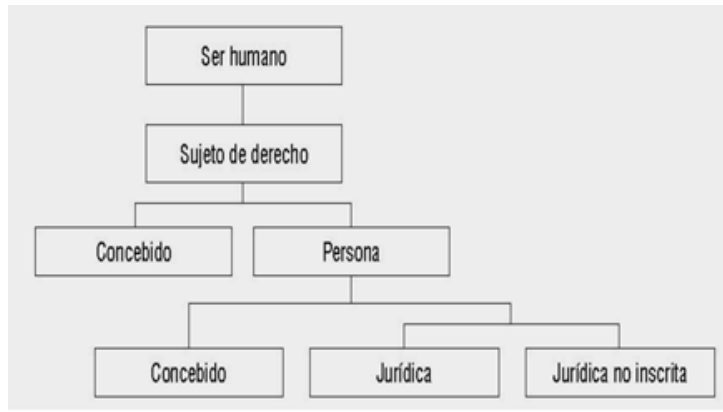

El sujeto de derecho, como institución jurídica que consagra el actuar del hombre en sociedad, es el género puesto que representa el contexto universal o global que configura la categorización jurídica de la vida humana. Mientras que los tipos que de la teoría general se originan, esto es, las clases de sujetos de derecho, se presentan como la especie, teniendo entre ellos al concebido, la persona natural, la persona jurídica y el ente no personificado. De manera metódica quedaría plasmado de la siguiente manera (tabla 2):

\begin{tabular}{|l|l|l|l|l|}
\hline Género & \multicolumn{4}{|l|}{ Sujeto de derecho } \\
\hline Especie & Concebido & $\begin{array}{l}\text { Persona } \\
\text { natural }\end{array}$ & $\begin{array}{l}\text { Persona } \\
\text { jurídica }\end{array}$ & $\begin{array}{l}\text { Ente no } \\
\text { personificado }\end{array}$ \\
\hline
\end{tabular}

Visto gráficamente tendríamos que el sujeto de derecho es el genus, mientras que el concebido, la persona natural, la persona jurídica y el ente no personificado se presentan como la spes. Como diría Césare Magni(5,1), el sujeto de derecho es el símbolo primario y la persona, el símbolo derivado, a lo cual nosotros agregaríamos los demás sujetos. Lo importante de esta sistematización es que, dentro del género, con su doctrina sólida y establecida, pueden ir acondicionándose nuevos tipos de sujeto, mientras que en la especie se indicarán y consagrarán las facultades y deberes, así como relaciones típicas que han de corresponder a cada ser jurídico.

\subsection{Concebido}

Es aquel ser humano que se encuentra en un estado de desarrollo biológico primario, sea in utero, estado gestional o ex utero, por implantarse o crioconservado.

Este estado es apreciado de una manera singular por el Derecho, otorgándolo un trato especial, diferencial, propio para su situación biológica. El concebido no es un sujeto de derecho común, sino, a contrario sensu, es un sujeto de derecho sui géneris, especial y único.

Esta característica en su tratamiento se debe a que goza per se de dos situaciones jurídicas:

La atribución de los derechos patrimoniales está supeditada a que nazca vivo.

La teoría de los efectos favorables.

\section{A. Natimorto}

Dentro del status de concebido debemos considerar al natimorto (natimuerto o nado morto L'enfant mortné para los franceses), aquel conce- 
bido que muere en el útero o durante el parto, llamado óbito fetal, y habiendo tenido vida intrauterina se le categoriza como un concebido, un concebido que falleció. No es persona porque no nació, pero al haber sido fruto de la fecundación adquirió la calidad de sujeto de derecho pasando, con su deceso, a ser un cadáver digno de respeto y protección. Fue concebido, vivió, pero no nació; ese vivir, sea en instantes o en tiempos más prolongados, marcó status iuris de sujeto de derecho especial.

\subsection{Persona natural}

Es aquel ser humano nacido. El hombre de carne y hueso.

A la persona, como sujeto de derecho común, se le aplican las relaciones jurídicas sin ningún tipo de restricción o reserva, a menos de que esté de por medio alguna causa de incapacidad o de haber restringido sus derechos.

\subsection{Persona jurídica}

Es aquel ente corporativo. Ente, organización.

El grupo de personas reunidas a efectos de poder satisfacer sus necesidades y cumplir sus anhelos de manera colectiva, habiéndose ceñido a una forma establecida por la ley y que consta inscrita en el registro correspondiente.

Cuenta con una autonomía y capacidad propia en las relaciones jurídicas que genere, esto implica que la persona jurídica es distinta legalmente, independiente, a sus integrantes.

\subsection{Ente no personificado}

Es aquel grupo de personas que se han reunido a efectos de poder satisfacer sus necesidades y cumplir sus anhelos de manera colectiva, pudiéndose haber sujetado a una forma establecida por la ley, pero que no han cumplido con el requisito de la inscripción en el registro correspondiente.

Las relaciones jurídicas son asumidas por sus integrantes de manera solidaria. Podríamos decir que el ente no personificado es un sujeto de derecho dual, i.e. responden individualmente sus integrantes, pero actúan colectivamente.

\section{Otros sujetos de derecho considerados en la ley civil nacional}

La legislación nacional gira en torno a la persona, ya que se encarga de regular cada una de sus vivencias, relaciones y conductas. Sin embargo, en casos especiales es de necesidad que el Derecho dicte normas concretas y típicas para ordenar y canalizar la defensa y protección de la vida humana en relación con alguna actividad, acontecimiento o situación dada. Existen, siguiendo esta lógica, normas que protegen de manera categórica y exclusiva al niño, al paciente, a la mujer, a la embarazada, al discapacitado, al trabajador, a los ancianos que se presentan como nuevos estados sociales, produciéndose — como dice Tobías - un retorno a los estatus(6), su tratamiento especial se debe a que sus estados ameritan un tratamiento específico, particular y propio en razón de que se trata de débiles jurídicos.

Ello no implica una regulación tangencial a las normas del Código en materia de la teoría del sujeto de derecho; por el contrario, es una normativa paralela compuesta por normas complementarias e integrativas, cuyo fin es reconocer que los estados actuales son categorías o situaciones de protección(6:398) y que, si bien se dan diferencias en el trato entre grupos de personas, esta diferenciación no afecta el principio de igualdad ante la ley, sino que, a contrario sensu, procura establecer una igualdad real o sustancial, incorporando nuevas formas de derechos a la persona, no en cuanto a individuo, sino en cuanto a lo perteneciente a cierto conjunto o grupo de la sociedad(6:397).

Examinemos algunas normativas esenciales de nuestro medio en lo que a legislación especial se refiere, entre ellas tenemos:

\subsection{Código de los niños y adolescentes ${ }^{7}$}

Regula de manera especial al niño y adolescente.

La edad, el aspecto cronológico de la persona, sus primeros ańos y hasta que adquiere una madurez promedio, este Código les brinda especial atención.

Considera niño a todo ser humano desde su con-

${ }^{7}$ Aprobado por D.L. No 27337, Código de los Nin̄os y Adolescentes (DOEP, 07/08/2000). 
cepción hasta cumplir los doce (12) años de edad y adolescente desde dicha edad hasta los dieciocho (18) años. Dentro de esta lógica legal, el concebido es un nińo y, por tanto, goza de la protección que le otorga la legislación, incluso se ofrece una protección especial a la mujer gestante a efectos de garantizar el desarrollo pleno de la gestación y del concebido ${ }^{8}$.

\subsection{Ley General de Salud ${ }^{9}$}

$\mathrm{El}$ art. V, en concordancia con el art. 4 de la Constitución, señala que son sujetos de derecho especial en el cuidado de la salud: el discapacitado, el niño, el adolescente, la madre y el anciano en situación de abandono social; en tal sentido, es responsabilidad del Estado velar por bienestar general (entiéndase salud) de estos pacientes especiales que, dadas sus características físicas o psíquicas, se presentan como grupos vulnerables.

\subsection{Ley de la persona con discapacidad ${ }^{10}$}

Esta ley tiene la finalidad de establecer el marco legal para la promoción, protección y realización, en condiciones de igualdad, de los derechos de la persona con discapacidad, promoviendo su desarrollo e inclusión plena y efectiva en la vida política, económica, social, cultural y tecnológica (art. 1).

La persona con discapacidad es aquella que tiene una o más deficiencias físicas, sensoriales, mentales o intelectuales de carácter permanente que, al interactuar con diversas barreras actitudinales y del entorno, no ejerza o pueda verse impedida en el ejercicio de sus derechos y su inclusión plena y efectiva en la sociedad, en igualdad de condiciones que las demás (art. 2).

\section{Taxonomía moderna}

Nuestra normativa y dogmática nacional clasifica

\footnotetext{
${ }^{8}$ Otras normas complementan este criterio, por ejemplo, se evitarán los procedimientos de diagnóstico o de terapia que ocasionen exposición en el abdomen de una mujer embarazada o probablemente embarazada, a menos que existan fuertes indicaciones clínicas, en cuyo caso se deben tomar todas las medidas de protección para reducir las dosis al embrión o feto. Reglamento de Seguridad Radiológica, artículo 39 del D.S. No 009-97-EM, (DOEP, 29/05/1997). VARSI ROSPIGLIOSI, Enrique. Derecho Médico peruano. Fondo Editorial. Universidad de Lima. Lima, 2001, p. 127.

${ }^{9}$ Ley N ${ }^{\circ} 26842$ (DOEP, 20/07/1997).

${ }^{10}$ Ley N 29973 (DOEP, 24/12/2012).
}

de forma cuaternaria (por ser cuatro) y manera tradicional al sujeto de derecho de la siguiente manera (diagrama 3):

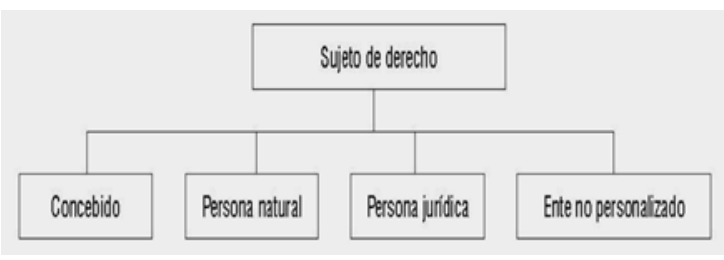

Sin embargo, la teoría del sujeto de derecho ha quedado disminuida frente a nuevos estados biológicos que merecen una protección especial, quizá ser catalogados como un nuevo elenco de sujetos de derechos. Tal es el caso de las células (somáticas y sexuales), el embrión no implantado, el embrión carente de signos vitales que ameriten una vida futura y aquel embrión que no generará un proceso biológico.

De acuerdo a un estudio doctrinario y casuístico, llegaremos a establecer que la categorización del sujeto de derecho compuesta solo por cuatro tipos ha venido siendo ampliada en la práctica y en las discusiones dogmáticas frente a aquellas que inflexiblemente han considerado la tradicional clasificación y cuaternaria taxonomía del sujeto de derecho.

No hay unanimidad de criterios en la regulación de los sujetos de derecho en los distintos códigos civiles del Derecho comparado. Algunos tratan del concebido como tal, independiente de los demás; otros regulan solamente a la persona natural y, dentro de ella, una subcategoría que denominan "persona por nacer" o nasciturus. Por su parte, hay aquellos que la acompañan con la persona jurídi$\mathrm{ca}$, mientras que otros ni la consideran en su regulación. El ente no personificado es reconocido legalmente de acuerdo con cada sistema jurídico y su tratamiento ha ido in crescendo durante las últimas décadas. Asimismo, hay códigos que tratan de los denominados seres jurídicos ideales, tal es el caso del concepturus (Alemania, Bolivia, Colombia e Italia).

Siendo obvia la falta de uniformidad de criterios normativos sobre la teoría del sujeto de derecho, menos aún en determinar quiénes y cuántos son en realidad, es que debe pensarse en el marco teó- 
rico acorde con nuestra realidad, así como en un replanteamiento de la institución. De esta forma nos preguntaríamos:

¿Qué será mejor en una norma civil? ¿Enumerar los sujetos de derecho a normar o desarrollar una sólida teoría general?

Para aproximarnos a una respuesta partamos de la premisa aceptada universalmente: el Derecho considera la vida en sí misma para preparar sus normas, sus códigos y, dado el avance vertiginoso de la sociedad y de la biotecnología, es de indispensable y urgente necesidad reconocer la variedad de formas de crear vida, de generar contenidos vitales que, de algún modo u otro, exigen la cautela del Derecho.

Siguiendo esta línea de pensamiento, es fácil vislumbrar que, fuera de la estructura clásica y tradicional, y no por ello menos real y efectiva, han venido surgiendo otros entes, con casi todas las características del sujeto de derecho, que exigen su enrolamiento en la exclusiva lista de seres jurídicos; es más, su afiliación y reconocimiento como nuevos sujetos, aparte de los cuestionamientos doctrinarios y dogmáticos, parece ser una nueva tendencia hacia la protección de la vida en su actual, verdadera y múltiple dimensión. Pero el tema central es que la visión que se tiene de la vida humana es cada vez es más amplia. Ya no hablamos solo del ser humano para referirnos al ser físico, psíquico y social, sino que el Derecho se ha visto en la necesidad de brindar protección al hombre en una dimensión mayor, como género humano; es así que se busca proteger, así como el todo, también las partes, es decir, el continente y el contenido, para referirnos directamente sus elementos, substancias, secuencias, células, etc.

Un diagrama nos puede ilustrar la nueva estructura que el Derecho genético quiere presentar a efectos de brindar una mayor seguridad a la vida humana (diagrama 4).

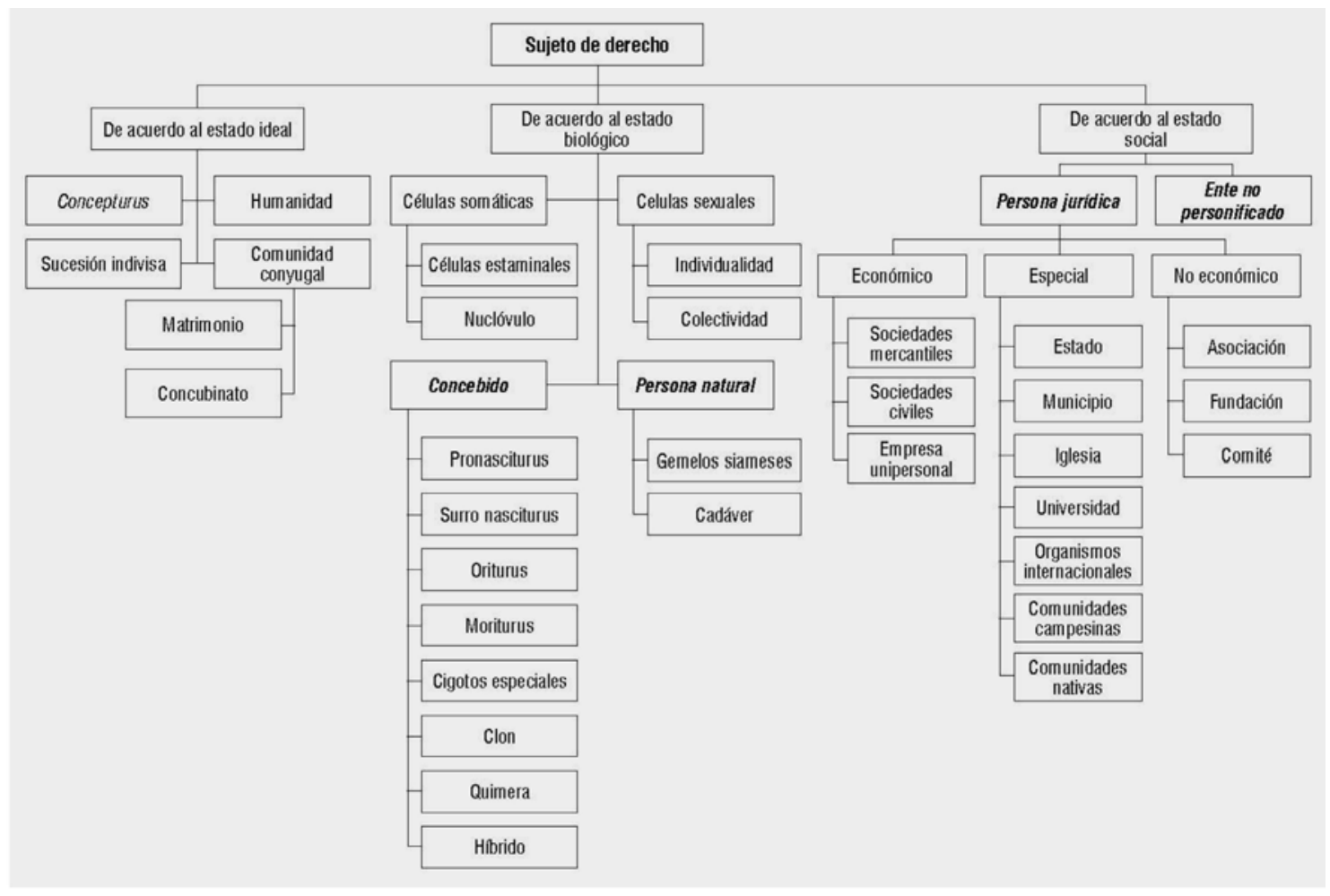




\subsection{De acuerdo a un estado ideal}

En el Derecho comparado se ha desarrollado, aparte del estado biológico y el social, una tercera situación —afianzada en un estado ideal- que busca ofrecer regulación a los denominados sujetos de derecho ideales.

En este tipo de situaciones el sujeto de derecho no existe, materialmente hablando, carece de una entidad física visible y palpable, su situación es esencialmente ideal. No tiene rostro ni rastro. Es un estado que se encuentra en la mente, en el pensamiento, deseo y sentir de las personas. No hay una materialidad en el sujeto de derecho sino una idealidad. No es viable ni palpable, solo dimensionable en el valor que le damos en nuestra conceptualización ideal. No obstante, la trascendencia de la voluntad de aquellos que quieren darle una vida legal a un deseo o aspiración y la connotación de las relaciones jurídicas generadas ha llevado a que el Derecho haya buscado una regulación especial.

\subsubsection{Concepturus}

Es aquel que será, que habrá de ser concebido.

Es parte de la idealización de la persona. El sujeto no existe, física ni biológicamente, pero puede atribuírsele relaciones jurídicas válidas, sujetas a determinada modalidad.

El concepturus es una institución propia del Derecho sucesorio y, en la actualidad, se ha llegado a zanjar doctrinal y jurisprudencialmente en el Derecho comparado que el mismo tiene vocación sucesoria, i.e. derecho a ser heredero o legatario. Tal es el caso contemplado por los códigos de Alemania, Bolivia, Colombia, Italia y Venezuela.

\subsubsection{Humanidad}

El desarrollo en el área de la biotecnología ha otorgado invalorables beneficios y, en muchos casos, también irreparables perjuicios que repercuten no solo en el ser humano, como sujeto de Derecho individual, sino también en su medio ambiente, en su entorno ecológico, así como en sus congéneres; la repercusión es difusa atentando contra la humanidad en general.

Hoc sensu, se protege de manera efectiva a la huma- nidad y ello se viene logrando bajo la teoría de asumirla como un nuevo tipo de sujeto de derecho, dado que la misma está esencialmente formada por seres humanos. La protección se da a la especie más que al individuo, pero, indiscutiblemente, beneficia también a éste de manera indirecta, dado que se busca conservar la esencia e integralidad de la humanidad.

Ya no se piensa solo en el individuo sino en la colectividad, no en el homo sino en el habitat. Es más, este esquema de categorización de la humanidad como sujeto de derecho robustece la teoría del concepturus, en el sentido de que, siendo la humanidad un ser jurídico ideal, entre lo que se considera a todos los seres humanos, incluso a las generaciones futuras o venideras ${ }^{11}$, merece una cautela jurídica especial.

Este similar razonamiento se ha venido logrando bajo el principio que el genoma humano es patrimonio de la humanidad y, como tal, merece la más amplia protección ${ }^{12}$.

\subsection{De acuerdo con un estado biológico}

Es un estado material. El sujeto de derecho existe en materia y contexto, siendo mensurable y dimensionable.

\subsubsection{Células somáticas}

Son aquellas que conforman los tejidos y órganos humanos. Su finalidad es regenerarse a fin de permitir la conservación de la vida. El avance de la ciencia ha permitido que estas células puedan cumplir funciones que no le son propias, como su utilización con fines reproductivos o la readquisición de la totipotencialidad.

$\mathrm{Al}$ respecto, debemos mencionar que tales prácticas con este tipo de células se dan generalmente en los casos de clonación, usándose para ello los núcleos de cualquier tipo de células somáticas humanas para fusionarlos con óvulos enucleados igualmente humanos; técnica que, de tener éxito,

\footnotetext{
${ }^{11}$ Declaración Universal de los Derechos Humanos de las generaciones futuras (Unesco, 1994), Declaración sobre las responsabilidades de las generaciones actuales sobre las generaciones futuras (Unesco, 1997).

${ }^{12}$ Declaración Universal sobre el Genoma Humano y los Derechos Humanos, art. 1.
} 
lograría que, a partir del empleo de parte de una célula somática (especializada), se puedan producir, artificial e inducidamente, todas las células que conforman el cuerpo humano, i.e. se lograría la vuelta a la indiferenciación de una célula ya diferenciada.

Estas células requieren un tratamiento jurídico especial con el fin de evitar su manipulación. Si bien no son vida humana (individual), son elementos humanos y, como tales, dignos de protección.

\subsubsection{Células estaminales}

Las células del cuerpo humano cumplen una función especial. Su objetivo está claramente establecido, lo que permite diferenciarlas de acuerdo con sus características y finalidades biológicas. Las células, que en grupos forman los órganos, tejidos y otros, tienen una función predeterminada, su estructura y capacidad está preparada para realizar una labor concreta, de allí que se diga que las células son diferenciadas.

Sin embargo, existen células indiferenciadas, i.e. que tienen todos los elementos necesarios para generar los diversos órganos o tejidos de un ser humano y podrían — vía inducción especial— generar un ser humano en su integridad, ya que, al no estar diferenciadas, contienen toda la información necesaria para dirigir un desarrollo completo. Estas células potenciales resultan atractivas para la biociencia, pues de ellas pueden extraerse tipos especiales de células (cardiacas, nerviosas, musculares, cerebrales, sanguíneas, cartilaginosas, etc.) y utilizarlas con fines terapéuticos.

Son llamadas células "madres", "troncales", "totipotenciales" o "primitivas" — conocidas en la terminología anglosajona como stem cells, y vienen representando un debate incontrolable en el ámbito jurídico y ético.

Según su origen, existen tres tipos de estas células estaminales:

\section{A. Células estaminales embrionales}

Las células de embriones normalmente son totipotenciales al encontrarse en un estado de preorganogénesis, i.e. al no estar definida su función, cualquiera célula puede dirigir su desarrollo a la obtención de determinado tejido humano. Se les conoce también como "células fetales".

Se obtienen mediante los siguientes pasos:

Producción de embriones o utilización de embriones sobrantes.

Desarrollo embrional hasta la fase de blastocito.

Ablación de su masa celular interna (ICM).

Cultivo de dichas células.

El problema esencial de estos procesos es que producen una vida con la única finalidad que sirvan de repuesto. Una vez extraídas, el daño que se ocasiona al embrión es irreparable, a punto tal que lo lleva a una muerte irremediable.

\section{B. Células estaminales adultas}

Un tipo de células adultas es capaz de producir determinados tejidos. Estas pueden reprogramarse a efectos que generen tejidos especiales, mediante técnicas de clonación celular con la finalidad de investigación terapéutica.

El objetivo es obtener células madre que, estimuladas, se conviertan en tejidos (óseo, muscular, nervioso, etc.) sirviendo para el tratamiento de enfermedades (Alzheimer, Parkinson, diabetes y cáncer) y para trasplantes en general.

Se obtienen mediante los siguientes pasos:

A una célula se le somete a un proceso de enucleación.

Se desnúclea un óvulo.

Transnucleación al óvulo del núcleo de la célula que queremos duplicar.

Es así que cuando se introduce el núcleo de una célula diferenciada de un individuo en un óvulo previamente desnucleado la célula resultante (paraclonación) —que no es el resultado de la fecundación (óvulo con espermatozoide) - es susceptible de desarrollarse a continuación como un embrión. Marcelo Palacios la denomina nuclóvulo ${ }^{13} \mathrm{e}$

\footnotetext{
13 "Una revolución con múltiples posibilidades". El País Digital
} 17/08/2000, No 1567. 
indica que, teniéndose en cuenta el distinto origen biológico del mismo, se establecen sutiles diferencias con el embrión.

\section{Células estaminales placentarias}

Este tipo de células tiene gran capacidad proliferativa y de diferenciación, ubicándose para su clasificación entre las embrionarias y las adultas.

\subsubsection{Células sexuales}

Son el espermatozoide y el óvulo. Su naturaleza jurídica es la de ser bienes o frutos naturales.

Bienes, porque tienen una utilidad, pues es la esencia y base de la procreación;

Fruto, porque son substancias renovables y natural porque es esencial y parte de la naturaleza.

Se les denomina también "células germinales" o "gametos". Su valor no es solo individual sino también social, de allí su necesaria protección. Contienen (al igual que las somáticas) el código genético individual, un genoma que es, por su naturaleza, fácilmente transferido en el momento de la fecundación.

Son fuerzas genéticas cuya finalidad es generar vida. Cuentan con la capacidad de reproducción de la especie humana, por lo que así resultan indisponibles. Como sustancias o secreciones que contienen el germen de la vida destinado a la procreación humana están fuera del comercio. Son protegidas no solo en su materialidad, sino principalmente en su potencialidad pasiva (a diferencia del embrión que es protegido por su potencialidad activa).

\subsubsection{Cigotos especiales}

Son producto de una seudofecundación.

Tenemos los siguientes casos: espermatozoide con espermatozoide (huevo masculino), óvulo con óvulo o del óvulo con la espermatogonia (proceso primario del espermatozoide).

\subsubsection{Clon}

El clon es producto de la alta tecnología repro- ductiva, pero no por ello deja de ser un sujeto de derecho.

La clonación es una forma de reproducción asexual mediante la que se crean individuos idénticos, tanto biológica como genéticamente, que comparten el mismo genoma. El hecho es que el clon no surge de una fecundación directa, de allí que se discuta acerca de su naturaleza jurídica.

Los tipos de clonación son:

Natural, es producida por el propio organismo viviente. Se da cuando una célula se divide (se fisiona), formando dos o más embriones. Es el caso de los gemelos univitelinos.

Artificial, es producto de la voluntad del hombre. En este caso la fecundación se realiza de manera asistida, extracorpórea y atípicamente (eutelegenesia), logrando engendrar de forma asexual un ser cuya característica es tener un código genético compartido con su genitor.

A su vez, la clonación artificial se presenta como:

Autorreproducción, tiende a reproducir a un ser humano ya existente. Este proceso consiste en la enucleación de un embrión y sustitución de su núcleo por el de otro embrión o de alguna otra célula.

Reproducción gemelar, busca engendrar individuos genéticamente idénticos entre sí. Este método se basa en seccionar el ovocito fecundado in vitro, con el fin de obtener embriones iguales.

Partenogénesis, este método permite el desarrollo del ovocito mediante técnicas de estimulación nuclear, sin la presencia de espermatozoides. En este proceso no hay fecundación.

Los casos en los que utiliza, o se ha pensado aplicar la clonación han sido los siguientes:

Con fines de investigación: el cultivo de embriones idénticos, estudio y conocimiento de la célula y avances en la investigación terapéutica.

Con fines reproductivos: para suplir la infertilidad, creación técnica de gemelos y crioconservación de ovocitos clonados, para permitir a las parejas ho- 
mosexuales tener descendencia.

Con otros fines no reproductivos: estudio del desarrollo embrionario, creación de un banco de órganos clónicos para trasplantes, crear vida para salvar otra vida y con fines eugenésicos para mejorar las razas.

\subsubsection{Quimera}

Es el embrión producto de la unión (fusión) de otros embriones. Su proceso de surgimiento no es propiamente la fecundación directa, sino que ha sido generado como consecuencia de la conjunción de dos o más embriones. Su paternidad es indeterminada, puesto que su código genético es un mosaico de líneas generacionales de los progenitores (bipaternidad o multipaternidad) que participaron en la fecundación de los embriones padres.

\subsubsection{Híbrido}

Es el intercambio de material genético de diferentes especies y se le conoce también como "transespeciación”. Los híbridos, conjuntamente con los procesos de clonación y las quimeras, representan otras de las desviaciones en el uso de las técnicas de reproducción asistida mediante procesos de manipulación genética.

Un ejemplo sería introducir material genético procedente de monos antropoides en un embrión humano y conseguir así seres híbridos de gran fuerza física y que estarían en la frontera de ambas especies.

¿Cuál sería su naturaleza? ¿Inhumanos, poshumanos, o infrahumanos?

\subsubsection{Embrión ex utero}

Llamado Fotus ex utero. El caso del embrión no implantado ha implicado la formulación de diversas opiniones acerca de su naturaleza jurídica, habiéndose argüido que:

No estando anidado, carece de las condiciones necesarias para permitir el desarrollo del ser humano, de allí que no deba ser considerado jurídicamente aún como vida humana.
Es un estado biológico que se encuentra paralizado y, como tal, no indica probabilidad alguna de vida.

Es una vida humana e, independientemente de la forma como ha sido creada y a la espera de su traslado a la pared uterina, merece la protección jurídica como sujeto de derecho.

La situación es clara. Si partimos del criterio general de que la vida humana se inicia con la concepción, desde dicho momento debemos garantizarla. No pueden permitirse diferenciaciones acerca de la forma, medio o situación biológica del embrión para atribuirle su categoría natural: ser un sujeto de derecho.

Dado la diversidad de estadios, se propone la terminología siguiente:

Nasciturus, para el embrión in utero.

Pronasciturus o nasciturus extracorporis, para el embrión ex utero, (el caso especial de los crioconservados).

Surro nasciturus, para el embrión transferido a tercera persona (caso de la maternidad subrogada).

\subsubsection{Oriturus}

Es aquel embrión que carece de viabilidad, de los elementos biológicos necesarios que le aseguren su desarrollo; su esperanza de vida es incierta. Es un término creado con el fin de restringir la naturaleza jurídica de la vida humana, permitiendo la manipulación genética sobre aquellos embriones que no cuentan con las características necesarias ni suficientes para permitir una vida.

La doctrina se refiere al oriturus respecto de aquel embrión o feto clínicamente no viable; una potencialidad humana que no tiene posibilidades de desarrollo embriológico, que carece de elementos genéticos suficientes para permitir la continuación y desarrollo de la vida. Concretamente, aquella vida que adolece de una inviabilidad relativa. Puede nacer, sí, pero con deformidades (esperanza de vida defectuosa).

Este término es utilizado en la jurisprudencia constitucional española al referir que: "Solo autoriza la 
donación y utilización de embriones o fetos que sean clínicamente no viables (i.e., potencialidades humanas que no tienen posibilidad de desarrollo embriológico y, por tanto, no son en estricto sentido nasciturus, sino oriturus) o estén muertos" ${ }^{\prime 4}$.

\subsubsection{Moriturus}

Es embrión que carece de signos vitales reales o que tiene tal grado de defecto biogenético que su estado derivará en una muerte inevitable. Adolece de una inviabilidad absoluta, produciéndose un aborto natural y necesario, su esperanza de muerte es cierta. En estos casos estamos frente a un ser humano que solamente espera su deceso, su muerte ante la inaptitud fisiobiológica que adolece, la que se producirá a los pocos momentos de nacer.

Es de indicar que científicamente se producen embriones inviables, que no tienen ninguna condición para llegar a crecer y formarse, so pretexto de justificar experimentaciones. Tal es el caso de embriones creados a través de procesos de poliespermia, es decir, óvulos fecundados por más de un espermatozoide, cuya consecuencia natural será indefectiblemente su aborto, o los embriones anencéfalos (sin cerebro). Estos embriones especiales o productos biológicos (como se les llama médicamente) representan un extraordinario potencial para la biomedicina y las técnicas de trasplantes.

La discusión que se plantea es si es viable su aborto.

\subsubsection{Gemelos siameses}

Es producto de una clonación frustrada. Cuerpos humanos compartidos. Son los gemelos que no terminan separándose.

Determinado que fuera el tipo de siamés, debemos preguntarnos si son dos o una persona. Analicemos algunos casos:

Si son dos cuerpos completos pero que se encuentran unidos y comparten órganos elementales, ha-

${ }^{14}$ STC 212/1996, del 19 de diciembre (Pleno). Recurso de inconstitucionalidad, Núm. 596/1989 referida a la Ley No 42/1988 sobre "Donación y utilización de embriones y fetos humanos o de sus células, tejidos y órganos". Ponente: Magistrado don Pedro Cruz Villalón (B.O.E. del 22 de enero de 1997). blaremos de dos sujetos de derecho.

Si es un solo cuerpo con dos cabezas, partiendo del análisis existencial de la vida diremos que serán dos seres humanos, cada quien con su mundo interior.

Si son dos cuerpos que nacen de una misma cabeza, será un solo ser humano.

El tema es complejo, más aún si para salvar la vida de un siamés debe sacrificarse al otro, sea porque tiene menos esperanza para sobrevivir o sea porque carece de órganos propios. La discusión ya se ha planteado, incluso ha llegado a los estrados judiciales y las decisiones que pueden tomar los padres para llegar a dicho momento no son unánimes.

\subsubsection{Cadáver}

No es exacto que el cadáver sea una nada jurídica: es una cosa y una cosa susceptible de ser objeto de actos jurídicos a la que se vinculan sentimientos muy respetables, según Borda(7).

Su naturaleza varía de acuerdo a los variados autores:

Semipersona, por la protección que se le brinda a su memoria e incolumidad de los restos(8).

Simple objeto de derecho, en su calidad de ser meros restos mortales (Caput mortuum), cosa, res.

Objeto de derecho especial, ex sujeto o sujeto existido digno de la más amplia protección, respeto y consideración. Debe tenerse en cuenta que los procesos biotecnológicos están incursionando sobre este elemento humano, de allí que la garantía jurídica sobre el mismo deba ser reconsiderada. No debemos preocuparnos solo por el tema de los actos de libre disposición y los trasplantes de órganos post mortem, sino que es de necesidad plantearse las hipótesis legales, a efectos de regular las experimentaciones genésicas que se vienen produciendo. 


\section{Referencias}

1. Fernández Sessarego C. Derecho de las personas. 11a edición. Lima: Grijley; 2009: 3.

2. Teixeira de Freitas A. Código Civil. Esbôço, tomo I. Río de Janeiro: Ministerio da Justiça e negocios interiores; $1952: 19$.

3. França R. Limongi. Instituções de Direito Civil. 5a edición, revisada y actualizada. São Paulo: Saraiva; 1999: 42.

4. Espinoza J. Derecho de las personas, tomo I. 6a edición. Lima: Grijley; 2012: 3.

5. Magni C. Sogetto e persona nel Diritto. En: Studi in onore de Vicenzo del Giudice. Milán: Giuffrè; 1953: 29.

6. Tobías J. W. Derecho de las Personas. Instituciones de Derecho Civil: parte general. $1^{\text {a }}$ edición. Buenos Aires: La Ley; 2009 : 13 y 397 y ss.

7. Borda G. El cadáver de una criatura nacida muerta es jurídicamente una cosa. La Ley 1981-B; 62.

8. Cifuentes S. Derechos personalísimos. Buenos Aires: Editorial Astrea; 1995: 406.

Recibido: 21 de marzo de 2016

Aceptado: 4 de mayo de 2016 